\title{
Antidiabetic Effects of Resveratrol: The Way Forward in Its Clinical Utility
}

\author{
Omolola R. Oyenihi, ${ }^{1}$ Ayodeji B. Oyenihi, ${ }^{2}$ \\ Anne A. Adeyanju, ${ }^{1}$ and Oluwafemi O. Oguntibeju ${ }^{3}$ \\ ${ }^{1}$ Department of Biochemistry, Bowen University, Iwo, Nigeria \\ ${ }^{2}$ Discipline of Biochemistry, School of Life Sciences, University of KwaZulu-Natal, Westville Campus, Private Bag X54001, \\ University Road, Durban 4000, South Africa \\ ${ }^{3}$ Nutrition and Chronic Disease Research Unit, Oxidative Stress Research Centre, Department of Biomedical Sciences, \\ Faculty of Health and Wellness Sciences, Cape Peninsula University of Technology, Bellville, South Africa
}

Correspondence should be addressed to Omolola R. Oyenihi; ooyenihi@sun.ac.za

Received 11 May 2016; Revised 15 August 2016; Accepted 26 October 2016

Academic Editor: Mark A. Yorek

Copyright (C) 2016 Omolola R. Oyenihi et al. This is an open access article distributed under the Creative Commons Attribution License, which permits unrestricted use, distribution, and reproduction in any medium, provided the original work is properly cited.

\begin{abstract}
Despite recent advances in the understanding and management of diabetes mellitus, the prevalence of the disease is increasing unabatedly with resulting disabling and life-reducing consequences to the global human population. The limitations and side effects associated with current antidiabetic therapies have necessitated the search for novel therapeutic agents. Due to the multipathogenicity of diabetes mellitus, plant-derived compounds with proven multiple pharmacological actions have been postulated to "hold the key" in the search for an affordable, efficacious, and safer therapeutic agent in the treatment of the disease and associated complications. Resveratrol, a phytoalexin present in few plant species, has demonstrated beneficial antidiabetic effects in animals and humans through diverse mechanisms and multiple molecular targets. However, despite the enthusiasm and widespread successes achieved with the use of resveratrol in animal models of diabetes mellitus, there are extremely limited clinical data to confirm the antidiabetic qualities of resveratrol. This review presents an update on the mechanisms of action and protection of resveratrol in diabetes mellitus, highlights challenges in its clinical utility, and suggests the way forward in translating the promising preclinical data to a possible antidiabetic drug in the near future.
\end{abstract}

\section{Introduction}

Resveratrol (3, 5, 4'-trihydroxy-trans-stilbene) is a nonflavonoid polyphenolic compound belonging to the stilbenoid class. It is the most relevant among stilbenes, due to its wellknown bioactivity. It was first identified in 1940 by Michio Takaoka from hellebore roots (Veratrum grandiflorum O. Loes) and it was from this source that the name "resveratrol" was derived [1]. In 1963, Nomomura also isolated it from the Japanese knotweed Polygonum cuspidatum before Siemann and Creasy later discovered it in wine in 1992. Resveratrol (RSV) is a natural phytoalexin found in wine. The consumption of red wine was linked to the low mortality of the French population and the term "French Paradox" was used to explain the observation of low mortality despite high risk of cardiovascular diseases (CVD). However, RSV is present at very low concentration [2], suggesting that the tag on RSV, "the red wine molecule," was overhyped. Regardless of whether or not the French Paradox involves RSV, a plethora of preclinical and clinical studies have demonstrated its beneficial effects [3]. RSV can also be found in grapes, variety of berries, peanuts, soy, and dark chocolate at different concentrations as shown in Table 1.

Structure-activity relationship seems to be crucial in the determination of the biological activities of RSV. The chemical structure of RSV consists of two aromatic rings linked by a methylene bridge and has been reported to exist in cis- and trans-stereoisomeric forms (Figure 1). However, the trans-isoform is the biologically active type [4]. During its metabolism, RSV undergoes a biotransformation by CYP1B1, a cytochrome P450 enzyme, to its monohydroxylated form, piceatannol [5]. This metabolite 
<smiles>Oc1ccc(/C=C/c2cc(O)cc(O)c2)cc1</smiles>

trans-resveratrol<smiles>Oc1ccc(/C=C\c2cc(O)cc(O)c2)cc1</smiles>

cis-resveratrol

FIGURE 1: Chemical structures of resveratrol.

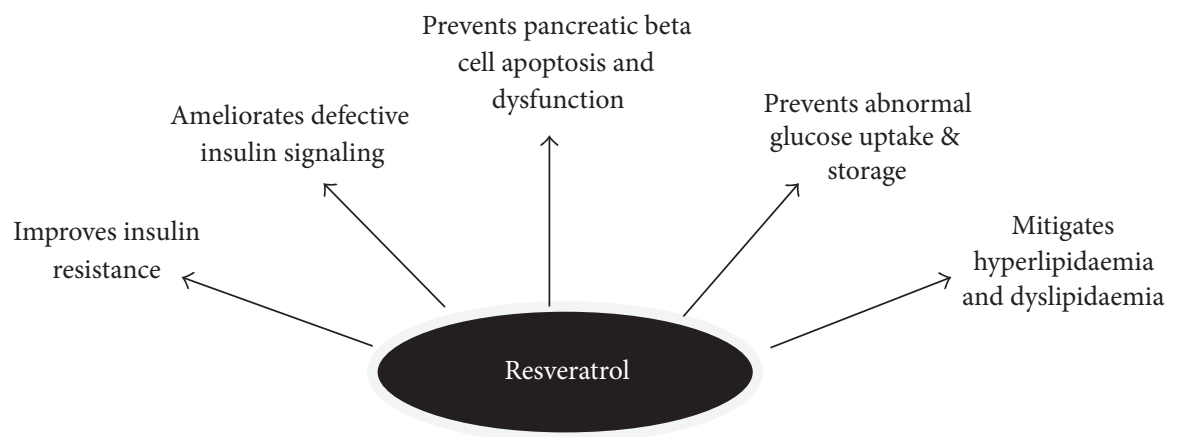

FIgURe 2: Protective effects of resveratrol in diabetes mellitus, adapted from [59, 64, 71, 120-122].

TABLE 1: Common sources of resveratrol and their estimated concentrations.

\begin{tabular}{lc}
\hline Sources of resveratrol & Resveratrol concentration \\
\hline Bilberries & $\sim 16 \mathrm{ng} / \mathrm{g}$ \\
Blueberries & $\sim 32 \mathrm{ng} / \mathrm{g}$ \\
Cranberry juice & $\sim 0.2 \mathrm{mg} / \mathrm{L}$ \\
Cocoa powder & $\sim 1.85 \mu \mathrm{g} / \mathrm{g}$ \\
Dark chocolates & $\sim 0.35 \mu \mathrm{g} / \mathrm{g}$ \\
Milk chocolate & $\sim 0.10 \mu \mathrm{g} / \mathrm{g}$ \\
White grape juice & $\sim 0.05 \mathrm{mg} / \mathrm{L}$ \\
Red grape juice & $\sim 0.50 \mathrm{mg} / \mathrm{L}$ \\
White grape seeds extract & $0.25 \mathrm{mg} / \mathrm{g}$ \\
Red grape seeds extract & $0.27 \mathrm{mg} / \mathrm{g}$ \\
White wines & $<0.1-2.1 \mathrm{mg} / \mathrm{L}$ \\
Red wines & $0.1-14.3 \mathrm{mg} / \mathrm{L}$ \\
Peanut & $0.02-1.92 \mu \mathrm{g} / \mathrm{g}$ \\
Peanut butter & $0.3-1.4 \mu \mathrm{g} / \mathrm{g}$ \\
Pistachios & $0.09-1.67 \mu \mathrm{g} / \mathrm{g}$ \\
\hline
\end{tabular}

Sources: [123-126].

was found to possess a stronger activity than RSV probably due to the presence of more hydroxyl groups that led to increase in inhibitory activities on nuclear factor kappa$\mathrm{B}(\mathrm{NF}-\kappa \mathrm{B})$ [6] and its inducer activity on apoptosis [7]. Ovesná and Horváthová-Kozics [8] described that transstilbene compounds containing ortho-diphenoxyl or paradiphenoxyl functional groups with $4^{\prime}$-hydroxyl group and double bond presented a high chemoprevention. In addition, the number and position of carboxyl groups, intramolecular hydrogen bonding, stereoisomerism, and presence of double bonds have been reported to influence its biological activity.

RSV has elicited beneficial effects in cardiovascular disorders, cancer, diabetes, obesity, amyloidogenesis, and others [9-13]. Some of these beneficial effects occurred via mechanisms such as anti-inflammation [14]; antioxidation [15]; antihyperglycaemia [16]; vasodilation [17]; and clearance of amyloid $\beta(\mathrm{A} \beta)$ peptides [18]. The molecular targets of RSV may include sirtuin 1 (SIRT1), adenosine monophosphate activated kinase (AMPK) [19-23], nuclear factor-kappa B $(\mathrm{NF}-\kappa \mathrm{B})[22,24,25]$, and kelch-like ECH-associated protein 1 (Keap-1)/nuclear factor erythroid 2-related factor 2 (Nrf2) [24].

The high safety profile of RSV, coupled with its multidirectional effects, has stimulated the interest of the scientific community making it an attractive candidate in the protection against the deleterious effects of hyperglycaemia. A large body of evidence has shown that RSV exerts protective effects in DM via several mechanisms as summarized in Figure 2. Despite the numerous preclinical data on the antidiabetic effects of RSV, there is limited evidence on its beneficial effect in diabetic humans. The aim of this review is to present an update on the evidence supporting the antidiabetic effects of RSV in DM and directions for future research.

\section{Diabetes Mellitus}

Diabetes mellitus (DM), a long-term, multifactorial, metabolic disease of severe complications, remains a global health challenge in the 21st century. According to a recent estimate 
of the International Diabetes Federation (IDF), DM has caused approximately 5 million deaths in the year 2015 out of the 415 million adults suffering from the disease [26]. The increasing morbidity and mortality rates observed among diabetic patients are majorly due to the high incidence and severity of diabetic complications which occur due to lack of proper management and persistent hyperglycaemia in DM. Uncontrolled progression of DM leads to the developing damages in the liver, kidney, brain, retina, heart, nerve, and blood vessel [27]. The current therapeutic options employed in the management of the disease have serious limitations due to adverse effects and reduced efficacy over time. Therefore, the search for more efficient antidiabetic drugs is on-going.

DM arises from major defects in insulin secretion, activities, or both [28]. The two major types are insulindependent diabetes mellitus (IDDM-type 1) and non-insulindependent diabetes mellitus (NIDDM-type 2). The former is characterized by selective autoimmune destruction of insulin producing pancreatic $\beta$-cell and insulin deficiency whereas the latter is a case of insulin resistance coupled with impaired insulin secretion [29]. It is evident that the inability of the pancreatic $\beta$-cells to produce enough effective insulin to maintain glycaemic control is a feature of both types of DM. Autoimmunity, genetic makeup, and environmental factors are responsible for pancreatic islets destruction [30] whereas obesity, nutritional disorders, hypertension, lifestyle habits, and genetic/hereditary factors have been implicated in insulin resistance and type $2 \mathrm{DM}$ through their effects on glucose metabolism [14].

Hyperglycaemia (a major characteristic of type 1 DM) results when the rate of glucose production far exceeds its utilization and storage. The result is a persistent increase in blood glucose level [31]. The high blood glucose pool is a consequence of some underlying predisposing factors such as inadequate insulin secretion by autoimmune-induced partially destroyed pancreatic $\beta$-cells, ineffective sensitization, and activation of insulin receptors/signal messengers. Overall, these factors consequently lead to derangements in metabolic processes such as glucose, lipid, and protein metabolism. Factors that aggravate the hyperglycaemic state involve increased mobilization of liver glycogen stores and hepatic gluconeogenesis, impaired glucose utilization, rapid mobilization of triglycerides, dysregulation of protein catabolism, and elevated blood levels of glucogenic amino acids which serve as gluconeogenic precursors [32].

Although the precise aetiopathogenesis of DM is still under debate, oxidative stress, inflammatory factors, and autoimmune reactions have all strongly emerged as the major pathogenic effectors for DM [33]. Oxidative stress results from overproduction of reactive oxygen species (ROS) and reactive nitrogen species (RNS) or the inadequate disposal of these species by antioxidants resulting in multiple deleterious effects on cellular metabolism. An antioxidant has been defined as any substance that when present at low concentration compared with those of an oxidizable substrate significantly delays or prevents oxidation of that substrate [34]. When an imbalance ensues between oxidant generation and antioxidant defence, the consequence is oxidative stress. Enormous evidence has emerged to support the role of oxidative stress in the pathogenesis of DM and in the development of vascular complications [31,35]. Excessive elevation of blood glucose directly causes $\beta$-cell stress, impairment of $\beta$-cell function, and survival, through generation of ROS and RNS [36]. Generation of these free radicals in DM can occur through mitochondrial superoxide overproduction, nonenzymatic glycation of proteins, glucose oxidation, overactivity of the hexosamine pathway, and activation of protein kinase $\mathrm{C}$ isoforms [37]. Excess ROS has the capacity to attack DNA, lipids, proteins, and carbohydrates forming harmful products/complexes such as advanced lipid and glycation end-products that cause deleterious consequences in the body [38]. The generation of excess free radicals, lipid peroxidation products, protein/carbohydrate oxidation products, and DNA adducts has been observed in a variety of in vitro and in vivo diabetic animal models [39].

Free radicals can also be produced by inflammatory cells at the site of inflammation leading to exaggerated oxidative stress [40]. Free radicals can initiate intracellular signaling cascade that enhances the synthesis of inflammatory mediators. Inflammation and oxidative stress are therefore "essential partners" in DM as both processes contain mechanisms for mutual amplification. Therefore, it has been proposed that a candidate antidiabetic drug should be one that possesses polypharmacological abilities due to the multipathogenicity of DM.

\section{Mechanisms of Protection of Resveratrol in Diabetes Mellitus (Preclinical Data)}

RSV has been reported to mitigate the harmful effects of DM in several in vitro and in vivo animal experiments through divergent mechanisms [32]. These mechanisms range from the reduction of blood glucose concentration (by increasing glucose uptake, utilization, and storage and increasing insulin sensitivity) and the restoration of abnormal insulin signaling pathways (by silencing the transcription of some genes or inactivation of proteins). The development of complications such as nephropathy, neuropathy, retinopathy, and cardiovascular diseases is primarily responsible for the increase in morbidity and mortality rates among diabetic individuals worldwide [27, 41]. Several interconnected pathways have been postulated to hasten the progression of DM to diabetic complications. Some protective mechanisms through which RSV act against these pathways are illustrated in Figure 3. Studies have shown that RSV improves biochemical and clinical parameters in both type 1 and type 2 animal models of diabetic nephropathy $[25,42,43]$; diabetic neuropathy $[3$, 44, 45]; diabetic retinopathy [20, 46-48]; diabetes-induced hypertension $[49,50]$; diabetes-induced cardiovascular diseases [22, 51, 52]; and diabetes-induced liver injury [53, 54].

3.1. Mechanisms to Combat Hyperglycaemia. High blood glucose concentration has the capacity to destroy pancreatic $\beta$-cells resulting in significant reduction of insulin secretion. As a mechanism to reduce hyperglycaemia, RSV has been shown to promote an increase in pancreatic $\beta$ cell population [55] and trigger an increase in the secretion of insulin $[56,57]$. As more insulin is secreted, excess blood glucose may be 


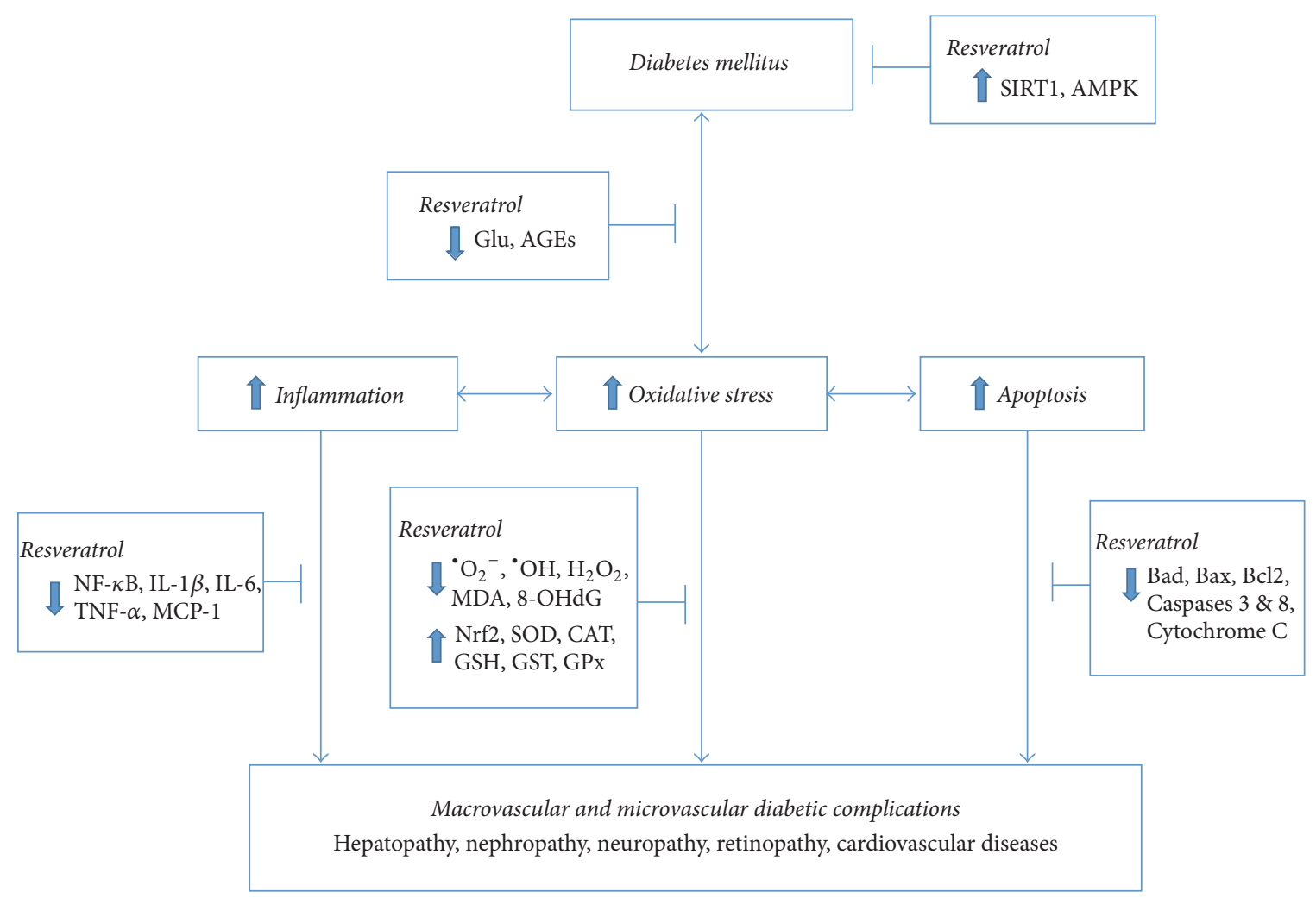

FIGURE 3: A simplified scheme showing mechanisms of resveratrol protection against the development of diabetic complications. SIRT1, sirtuin-1; AMPK, adenosine monophosphate activated kinase; Glu, glucose; AGEs, advanced glucose end-products; ${ }^{\circ} \mathrm{O}_{2}{ }^{-}$, superoxide anion; ${ }^{\circ} \mathrm{OH}$, Hydroxide radical; $\mathrm{H}_{2} \mathrm{O}_{2}$, hydrogen peroxide; MDA, malondialdehyde; 8-OHdG, 8-hydroxydeoxyguanine; Nrf2, nuclear factor erythroid 2-related factor 2; SOD, superoxide dismutase; CAT, catalase; GSH, reduced glutathione; GST, glutathione S-transferase; GPx, glutathione peroxidase; NF- $\kappa \mathrm{B}$, nuclear factor-kappa B; IL, interleukin; TNF, tumour necrosis factor; MCP, monocyte chemoattractant protein; Bcl2, B-cell lymphoma 2; Bad, Bcl-2-associated death promoter; Bax, bcl-2-like protein 4.

either stored as glycogen or utilized by tissues until glucose homeostasis is restored and maintained. The induction of glycogenesis in liver and skeletal muscle has been reported in diabetic rats following RSV administration [58]. Also, RSV treatment causes an increase in glucose uptake via the translocation of GLUT-4 to the membrane in diabetic rats [59]. Furthermore, RSV has been demonstrated to ameliorate hyperglycaemia-mediated disturbances in lipid and protein metabolism in rats supporting its antidiabetic actions [54, 60].

Impaired glucose tolerance (IGT) is a condition where the elevation of blood glucose level is not considered high enough to be classified as DM. This condition normally precedes a full-blown hyperglycaemia. It has been postulated that an intensive management of IGT in susceptible individuals may be critical in preventing the onset of DM [61]. In high-fat dietfed mice, RSV was shown to significantly improve glucose tolerance $[62,63]$. Similar improvement in glucose tolerance has been reported in diabetic rats $[64,65]$ and this effect has been proposed to occur primarily through AMPK-dependent mechanisms [66]. The ability of RSV to improve oral glucose tolerance has also been demonstrated in normal nonhuman primates chronically fed with RSV-supplemented diet [67].
Dysregulated insulin signaling is an integral factor in the development of insulin resistance and type 2 DM [68]. Excess blood glucose level increases the production of free radicals and advanced glycated end-products (AGE) that may inhibit proteins and enzymes involved in the insulin signaling pathways leading to the development of insulin resistance. Also, AGE has been shown to trigger stress signals that modify insulin receptor substrate proteins by increasing their serine/threonine phosphorylation and are subsequently destroyed partly contributing to insulin resistance [69]. RSV has been reported to induce p-Akt expression in STZ-diabetic rats $[59,70]$. Furthermore, RSV was recently shown to improve IRS-1 mediated insulin signaling through inhibition of protein tyrosine phosphatase (PTP) 1B expression in liver and muscle of diabetic rats [71]. In addition, RSV was reported to downregulate the expression of receptor for AGE (RAGE) in diabetic rat tissues [72, 73]. Therefore, RSV amelioration of AGE-induced dysregulated insulin signaling through the inhibition of AGE production and activities may partly contribute to its antihyperglycaemic property in DM.

RSV may exert its antihyperglycaemic effects through the activation of SIRT1. SIRT1, an NAD ${ }^{+}$-dependent deacetylase, has been described as an important regulator of many factors influencing type $2 \mathrm{DM}[21,63,74]$. Studies have revealed that 
SIRT1 activity and expression were decreased significantly in in vitro and in vivo experimental models of DM [75, 76]. However, the administration of RSV was reported to normalize hyperglycaemia in obese mice with DM partly through the activation of SIRT1 [77]. In a recent study, an intraduodenal infusion of RSV improved insulin sensitivity and lowered hepatic glucose production in three rat models of insulin resistance [78]. The glucoregulatory effects of RSV in the study were attributed to the activation of SIRT1 and AMPK. The results from the same study were further supported by a development of hepatic insulin resistance in rats fed normal chow following a duodenum-specific knockdown of SIRT1 expression for 14 days.

The antidiabetic effects of RSV may be linked to the activation of SIRT1 mechanistic pathways. Upon activation, SIRT1 was reported to deacetylate forkhead box protein (FOX) O1, inhibiting its activity and consequently suppressing pancreatic $\beta$-cell apoptosis [79]. The FOXO1-mediated induction of transcription factors MafA and NeuroD, which play important roles in the survival of pancreatic $\beta$-cells, may be sustained by the activation of SIRT1. This action results in enhanced insulin sensitivity and improved regulation of glucose homeostasis [80]. In addition, SIRT1 has been shown to deacetylate PTP1B reducing its activity and leading to the improvement of insulin sensitivity in insulinresistant conditions [81]. In experimental animals, activation of SIRT1 was reported to offer protection against obesity and insulin resistance by positively regulating the secretion of insulin [82]. The regulation of insulin secretion by SIRT1 has also been shown to trigger glucose uptake and utilization [83]. Experimental studies in pancreatic $\beta$-cells in mice have revealed an improvement in glucose tolerance and enhancement of insulin secretion when the dose of SIRT1 was increased $[84,85]$. The stimulation of insulin secretion by SIRT1 has been suggested to occur via transcriptional repression of uncoupling protein 2 (UCP2). In pancreatic $\beta$ cells, the overexpression of SIRT1 has been shown to increase ATP via the repression of UCP2 leading to cell membrane depolarization and $\mathrm{Ca}^{2+}$-dependent insulin exocytosis [86].

Furthermore, some of the beneficial effects of RSV on the regulation of glucose homeostasis may be mediated through the activation of AMPK. AMPK regulate several important intracellular processes such as energy metabolism, mitochondrial functions, and cellular homeostasis [32]. AMPK is activated mainly by a low cellular energy status (high AMP/ATP ratio), elevated intracellular nucleotide adenine dinucleotide $\left(\mathrm{NAD}^{+}\right)$concentration, and the catalytic actions of cyclic nucleotide phosphodiesterase (PDE). Energy stress conditions like diet restriction, hypoxia, exercise, and fasting are very strong factors for the activation of AMPK [87]. Once activated majorly by phosphorylation, AMPK promotes the inhibition of processes that utilize ATP or inhibits ATP production in the cell. Under hyperglycaemic conditions, the dysregulation of AMPK activity correlated with insulin resistance and hyperglycaemia-associated tissue damage [88], supporting a key role of AMPK in type $2 \mathrm{DM}$. The effects mediated by RSV via AMPK activation include the regulation of insulin sensitivity, increase in glucose uptake, and regulation of insulin secretion in pancreatic $\beta$-cells [66]. The alleviation of diabetic complications upon the activation of AMPK by RSV has been confirmed in animal models [15, 19, 59, 89]. Also, AMPK activation has been shown to be initially triggered by RSV-induced activation of SIRT1 leading to increased mitochondrial biogenesis and function [90].

3.2. Mechanisms to Combat Oxidative Stress. One of the main mechanisms responsible for the antidiabetic effects of RSV involves its antioxidant actions. In diabetic rat tissues, RSV has been reported to normalize the concentration of oxidative stress indicators such as superoxide anion $\left(\mathrm{O}_{2}{ }^{--}\right)$, hydroxyl radical $\left(\mathrm{OH}^{*}\right)$, hydrogen peroxide $\left(\mathrm{H}_{2} \mathrm{O}_{2}\right)$, malondialdehyde (MDA), thiobarbituric acid reactive substances (TBARS), 8-isoprostane, 8-hydroxydeoxyguanine (8OHdG), nitro-tyrosine (nitro-Tyr), reduced/oxidized glutathione (GSH/GSSG) ratio, and nitrite/nitrate ratio [24, 5254, 91-93]. Furthermore, RSV has been reported to exhibit its antioxidant activities by increasing the activities of antioxidant enzymes such as superoxide dismutase (SOD), catalase (CAT), glutathione peroxidase (GPx), glutathione reductase (GRed), glutathione S-transferase (GST), and quinone reductase (QRed) as well as increasing the levels of nonenzymatic antioxidant compounds (reduced glutathione and vitamins $\mathrm{C}$ and $\mathrm{E}$ ) in diabetic animals $[24,48,52,53,94]$.

Apoptotic cell death is a consequence of hyperglycaemiamediated oxidative stress. The effects of RSV on apoptosis in the kidney [95], heart [52], brain [96], testes [97], retina [48], and muscle [98] in diabetic animals have been reported. In these studies, RSV was shown to significantly reduce the apoptotic index coupled with a reduction in the levels of proapoptotic proteins in diabetic tissues.

In addition to the central role of SIRT1 in the regulation of glucose metabolism, mitochondrial function, and respiration biogenesis, it is also involved in cellular processes such as apoptosis, inflammation, oxidative stress, calorie restriction, and aging $[3,87,99,100]$. In type $1 \mathrm{DM}$, oxidative stress resulting from an increased generation of $\mathrm{O}_{2}{ }^{--}$accompanies the reduction in SIRT1 expression. Hence, activation of SIRT1 is a key protective effect against oxidative stress in type 1 DM. There have been reports indicating that the activation of SIRT1 by RSV suppresses ROS generation via the enhancement of the activity of FOXO3a [101] and upregulation of MnSOD expression [102].

Another molecular target of RSV is Nrf2 (nuclear factor erythroid 2- [NF-E2-] related factor 2), a transcription factor responsible for the constitutive and inducible expression of antioxidant response element- (ARE-) regulated genes [103]. The activation of the Nrf2/ARE pathway plays a major role in the protective action exerted by RSV against oxidative stress in DM by upregulation of cellular antioxidant defence mechanisms including heme oxygenase-1 (HO-1) and GPx [102]. RSV treatment of diabetic rats normalized the decreased renal expression of Nrf2 in hyperglycaemiamediated oxidative stress and upregulated its downstream regulatory proteins such as gamma-glutamylcysteine synthetase ( $\gamma$-GCS), $\mu$-GST, and HO-1 [24]. Under nonactivated conditions, Nrf2 interacts with Keap-1, thereby limiting Nrf2mediated gene expression. Upon activation by RSV, the 
Keap-1-Nrf2 complex dissociates and Nrf2, which is released from Keap-1, binds to ARE to upregulate the expression of genes in order to reduce oxidative stress.

3.3. Mechanisms to Combat Inflammation. As part of a coordinated response to the onslaught of ROS and other cellular stress signals, inflammatory cells (such as monocytes/macrophages, lymphocytes, platelets, granulocytes, and mast) are recruited. These cells propagate their activities through the activation of inflammatory mediators such as cytokines/chemokines, cell adhesion molecules, growth factors, and prostaglandins [104]. Altogether, the overactivation of these processes acts act synergistically to accelerate the severity of the clinical manifestations of DM and diabetesrelated complications.

RSV has been shown to elicit its anti-inflammatory properties in DM mainly via the inhibition of the nuclear factor $\mathrm{NF}-\kappa \mathrm{B}$ pathway. NF- $\kappa \mathrm{B}$ is a proinflammatory master switch, which activates proinflammatory cytokines gene expression and apoptosis cascade [105]. Upon activation, NF- $\kappa \mathrm{B}$ can mediate the transcription of inflammatory genes. Production and release of proinflammatory cytokines and chemokines induce ROS and RNS production and further increase tissue oxidative stress resulting in a vicious cycle of inflammation and oxidative stress. Thus, modulation of $\mathrm{NF}-\kappa \mathrm{B}$ may be an attractive treatment strategy in the treatment and management of DM. RSV administration has been reported to significantly decrease NF- $\kappa \mathrm{B}$ activity in the retinas of diabetic rats [48]. RSV also demonstrated inhibitory effect on NF- $\kappa \mathrm{B}$ activity and ameliorated the elevated levels of inflammatory proteins, TNF- $\alpha$ (tumour necrosis factor- $\alpha$ ), interleukin(IL-) 6, and COX-2 (cyclooxygenase 2), thus contributing to reduction in neuroinflammation and protection against functional and behavioural deficits in diabetic neuropathy [106]. The anti-inflammatory property of RSV has been confirmed in diabetic animals by the downregulation of proinflammatory genes and proteins like TNF- $\alpha$, IL-1 $\beta$, IL-6, IL-4, IL-17, COX-2 intercellular adhesion molecule 1 (ICAM), and vascular cell adhesion protein 1 (VCAM1) $[14,19,22,24$, $107,108]$ which are downstream targets of NF- $\kappa$ B. In addition, RSV significantly decreased the activation and recruitment of macrophages thereby retarding the inflammation process in diabetic rats $[22,109]$. Zhang and colleagues [110] reported that the anti-inflammatory effects of RSV in type 2 DM may be elicited via the downregulation of mRNA and protein expression of TNF- $\alpha$, a known inflammatory trigger resulting in the inhibition of TNF- $\alpha$-induced $\mathrm{NAD}(\mathrm{P}) \mathrm{H}$ oxidase activation, a key cellular source of $\mathrm{O}_{2}{ }^{--}$.

\section{Clinical Studies on the Effects of Resveratrol in Diabetes Mellitus}

Although numerous data exist on the beneficial outcomes of RSV in diabetic animals and in vitro, limited studies have specifically investigated the antidiabetic effects of RSV in humans $[16,111-113]$. A vast majority of clinical studies on the effects of RSV have focused on healthy individuals or other metabolic disorders but there is paucity of comprehensive information on its effects in diabetic humans (Table 2). It is interesting to note that the data obtained from majority of the clinical studies carried out in DM have been consistent with the promising results from animal models. One of these studies also reported improvement in diabetes complication (foot ulcer) after RSV treatment [113].

Bhatt and colleagues demonstrated that RSV (250 mg/day for 3 months) administered along with glibenclamide and/or metformin demonstrated improvement in glycaemic parameters in diabetic patients [16]. The study reported improvement in HbAlc, systolic blood pressure, and total cholesterol in patients with type $2 \mathrm{DM}$ treated with RSV combined with the oral hypoglycaemic agents. Brasnyó and colleagues [112] reported an improvement in insulin sensitivity in type 2 diabetic patients after treatment with a low dose of RSV ( $5 \mathrm{mg}$ twice daily) for 4 weeks. In the study, RSV treatment was shown to decrease HbAlc, systolic blood pressure, and total cholesterol. A decrease in oxidative stress assessed by measuring urinary orthotyrosine excretion was also reported. However, the authors found no evidence that RSV influenced homeostasis model of assessment of $\beta$-cell function (HOMA$\beta$ ) and therefore proposed that the mechanism of antidiabetic effects might be due to reduction in oxidative stress and a more efficient insulin signaling. Recently, Movahed and others [111] reported that $1 \mathrm{~g} /$ day of RSV supplementation for 45 days notably reduced fasting blood glucose, HbAlc, insulin, and systolic blood pressure. However, compared to the study of Brasnyó and colleagues [112] who observed no effect on HOMA- $\beta$ at the administered dose, data from the study of Movahed et al. revealed a decrease in HOMA$\beta$ as well as homeostasis model of assessment of insulin resistance (HOMA-IR). Another important observation from the two studies is that RSV not only complemented but also provided additional protection over standard antidiabetic medication.

Some beneficial outcomes have also been reported with RSV treatment in nondiabetic humans. In obese subjects, Timmers and colleagues [114] reported significant improvement in the metabolic profile and general health after RSV supplementation for 30 days thereby describing RSV as a calorie restriction mimetic. RSV showed beneficial effects on glucose homeostasis and insulin sensitivity; reduced intrahepatic lipid (IHL) content and expression of inflammatory genes; and improved mitochondrial efficiency. These effects may be associated with the activation of AMPK and increased SIRT1 and PGC- $1 \alpha$ protein content in the muscle [114]. In a double blind, randomized, placebo-controlled clinical trial, the effects of one-month RSV supplementation (40 mg/kg body weight) was assessed on endothelial response and inflammatory capacity in healthy subjects. A lowered expression of genes associated with inflammation and initiation of atherosclerosis such as VCAM, ICAM, IL-8, and $I F N-\gamma$ was observed following incubation of human coronary artery endothelial cells with plasma from participants [115].

Although several studies have reported the beneficial effects of RSV in clinical trials, some other studies have also shown no benefit. The daily administration of RSV at a dose of $150 \mathrm{mg}$ for 30 days improved metabolic parameters and modulated the putative molecular targets of RSV in obese men 
TABLE 2: Clinical trials on the effects of resveratrol.

\begin{tabular}{|c|c|c|c|c|c|}
\hline Subjects & $\begin{array}{l}\text { Conditions of the } \\
\text { subjects }\end{array}$ & $\begin{array}{l}\text { Number } \\
\text { of subjects }\end{array}$ & Dose and duration of study & Outcomes & References \\
\hline \multirow{5}{*}{$\begin{array}{l}\text { Diabetic } \\
\text { humans }\end{array}$} & Type 2 DM & 62 & $\begin{array}{l}250 \mathrm{mg} / \text { day }+ \text { oral } \\
\text { hypoglycaemic agents for } 3 \\
\text { months }\end{array}$ & $\begin{array}{l}\text { (i) Decreased HbAlc level } \\
\text { (ii) No effects on body weight, high-density } \\
\text { lipoprotein (HDL), and low-density lipoprotein } \\
\text { (LDL) cholesterols }\end{array}$ & [16] \\
\hline & Type 2 DM & 70 & $\begin{array}{l}500 \mathrm{mg} \text { twice daily for } 45 \\
\text { days }\end{array}$ & $\begin{array}{l}\text { (i) Decreased fasting blood glucose, HbAlc, } \\
\text { insulin, and insulin resistance, } \\
\text { (ii) Increased HDL level }\end{array}$ & {$[111]$} \\
\hline & Type 2 DM & 19 & $5 \mathrm{mg}$ twice daily for 4 weeks & $\begin{array}{l}\text { (i) Improved insulin sensitivity } \\
\text { (ii) Increased pAkt : Akt ratio in the platelets }\end{array}$ & {$[112]$} \\
\hline & Type 2 DM & 24 & $50 \mathrm{mg}$ twice daily for 60 days & $\begin{array}{l}\text { (i) Reduced foot ulcer size and plasma } \\
\text { fibrinogen level }\end{array}$ & [127] \\
\hline & $\begin{array}{l}\text { Type } 2 \mathrm{DM} \text { and } \\
\text { hypertensive patients } \\
\text { with coronary artery } \\
\text { disease }\end{array}$ & 35 & $\begin{array}{l}\text { RSV-enriched grape extract } \\
\text { for } 12 \text { months }(8 \mathrm{mg} / \text { day in } \\
\text { the first } 6 \text { month and } \\
16 \mathrm{mg} / \text { day in the last } 6 \\
\text { months) }\end{array}$ & $\begin{array}{l}\text { (i) No effect on serum glucose level, HbAlc, } \\
\text { lipids, and blood pressure } \\
\text { (ii) Decreased IL- } 6 \text { level and expression of } \\
\text { IL- } 1 \beta \text { and TNF- } \alpha\end{array}$ & {$[128]$} \\
\hline \multirow{9}{*}{$\begin{array}{l}\text { Nondiabetic } \\
\text { humans }\end{array}$} & $\begin{array}{l}\text { Obese men with no } \\
\text { family history of any } \\
\text { endocrine disorder }\end{array}$ & 11 & $\begin{array}{l}150 \mathrm{mg} / \text { day oral } \\
\text { administration for } 30 \text { days }\end{array}$ & $\begin{array}{l}\text { (i) Reduced hepatic steatosis } \\
\text { (ii) Decreased adipose tissue lipolysis } \\
\text { (iii) Decreased intrahepatic lipid content, } \\
\text { glucose, triglycerides, and inflammation } \\
\text { markers } \\
\text { (iv) Increased AMPK activation in muscle } \\
\text { (vi) Increased SIRT1 level }\end{array}$ & {$[114]$} \\
\hline & $\begin{array}{l}\text { Obese men with no } \\
\text { overt endocrine } \\
\text { disorders }\end{array}$ & 24 & $500 \mathrm{mg}$ thrice for 4 weeks & $\begin{array}{l}\text { (i) No detectable effects on insulin sensitivity, } \\
\text { gene expression of inflammatory biomarkers, } \\
\text { AMPK, and acetyl-CoA carboxylase }\end{array}$ & {$[116]$} \\
\hline & $\begin{array}{l}\text { Overweight/obese } \\
\text { men with mild } \\
\text { hypertriglyceridemia }\end{array}$ & 8 & $\begin{array}{l}2 \text { weeks }(1000 \mathrm{mg} / \text { day for } 1 \mathrm{st} \\
\text { week followed by } \\
2000 \mathrm{mg} / \text { day for } 2 \mathrm{nd} \text { week) }\end{array}$ & $\begin{array}{l}\text { (i) No effect on insulin sensitivity, fasting, or } \\
\text { fed plasma triglyceride concentration } \\
\text { (ii) Reduced apoB-100 and apoB- } 48 \text { production } \\
\text { rates }\end{array}$ & {$[117]$} \\
\hline & $\begin{array}{l}\text { Overweight or obese } \\
\text { men diagnosed with } \\
\text { NAFLD }\end{array}$ & 20 & $\begin{array}{l}3000 \mathrm{mg} / \text { day daily for } 8 \\
\text { weeks }\end{array}$ & $\begin{array}{l}\text { (i) No effect on insulin resistance and steatosis } \\
\text { (ii) No effect on plasma lipids or antioxidant } \\
\text { activity. } \\
\text { (iii) Increased levels of ALT and AST } \\
\text { (iv) No effect on mRNA levels of NQO1, PTP1B, } \\
\text { IL-6, or HO-1 }\end{array}$ & [118] \\
\hline & $\begin{array}{l}\text { Nonobese, } \\
\text { postmenopausal } \\
\text { women with normal } \\
\text { glucose tolerance }\end{array}$ & 45 & $75 \mathrm{mg} /$ day for 12 weeks & $\begin{array}{l}\text { (i) No effect on insulin sensitivity in the liver, } \\
\text { skeletal muscle, or adipose tissue } \\
\text { (ii) No effect on plasma lipid or inflammatory } \\
\text { markers } \\
\text { (iii) No effect on the expression of Ampk, Sirt1, } \\
\text { Nampt, and Pgc-1 } \alpha \text { in skeletal muscle or } \\
\text { adipose tissue }\end{array}$ & [129] \\
\hline & Healthy humans & 22 & $\begin{array}{l}250 \text { and } 500 \mathrm{mg} \text { for } 2 \text { study } \\
\text { visits of few days apart }\end{array}$ & $\begin{array}{l}\text { (i) Increased cerebral blood flow } \\
\text { (ii) No effect on cognitive function }\end{array}$ & [17] \\
\hline & Healthy humans & 46 & $200 \mathrm{mg} / \mathrm{day}$ for 26 weeks & $\begin{array}{l}\text { (i) Increased serum insulin level } \\
\text { (ii) Decreased HbAlc } \\
\text { (iii) Improved memory performance }\end{array}$ & [119] \\
\hline & Healthy humans & 44 & $\begin{array}{l}400 \mathrm{mg} \text { RSV }+400 \mathrm{mg} \text { grape } \\
\text { skin extract }+100 \mathrm{mg} \\
\text { quercetin for } 30 \text { days }\end{array}$ & $\begin{array}{l}\text { (i) Reduced plasma level of IFN- } \gamma \\
\text { (ii) Decreased expression of ICAM, VCAM, } \\
\text { and IL- } 8 \text { in endothelial cells }\end{array}$ & {$[115]$} \\
\hline & $\begin{array}{l}\text { Elderly individuals } \\
\text { with impaired } \\
\text { glucose tolerance }\end{array}$ & 10 & $\begin{array}{l}\text { Daily dose of } 1,1.5 \text {, or } 2 \mathrm{~g} \text { for } \\
4 \text { weeks }\end{array}$ & $\begin{array}{l}\text { (i) Improved insulin sensitivity } \\
\text { (ii) Reduced postprandial plasma glucose } \\
\text { (iii) No effects on body weight, blood pressure, } \\
\text { and lipid parameters }\end{array}$ & {$[130]$} \\
\hline
\end{tabular}


TABLE 2: Continued.

\begin{tabular}{|c|c|c|c|c|c|}
\hline Subjects & $\begin{array}{l}\text { Conditions of the } \\
\text { subjects }\end{array}$ & $\begin{array}{c}\text { Number } \\
\text { of subjects }\end{array}$ & Dose and duration of study & Outcomes & References \\
\hline & $\begin{array}{l}\text { Patients with stable } \\
\text { angina pectoris. }\end{array}$ & 166 & $20 \mathrm{mg} /$ day for 60 days & $\begin{array}{l}\text { (i) Decreased in serum levels of C-reactive } \\
\text { protein (CRP) } \\
\text { (ii) Decreased levels of lipid biomarkers }\end{array}$ & [131] \\
\hline & $\begin{array}{l}\text { Patients at high CVD } \\
\text { risk on statins } \\
\text { treatment for CVD } \\
\text { prevention }\end{array}$ & 75 & $\begin{array}{l}12 \text { months }(8 \mathrm{mg} / \text { day in the } \\
\text { first } 6 \text { months and } 16 \mathrm{mg} / \text { day } \\
\text { in the last } 6 \text { months) }\end{array}$ & $\begin{array}{l}\text { (i) Decreased CRP, TNF- } \alpha \text {, PAI type } 1 \text {, and } \\
\text { IL- } 6 / \text { IL - } 10 \text { ratio } \\
\text { (ii) Increased IL-10 level }\end{array}$ & [132] \\
\hline
\end{tabular}

ICAM: intercellular adhesion molecule; VCAM: vascular cell adhesion molecule; IL-8: interleukin-8; AMPK: adenosine monophosphate activated kinase; SIRT1: sirtuin-1; IFN- $\gamma$ : interferon gamma; NQO: NAD(P)H:Quinone oxidoreductase; Nampt: nicotinamide phosphoribosyltransferase; PGC: peroxisome proliferator-activated receptor gamma coactivator; CRP: C-reactive protein.

with no endocrine disorder [114]. However, its administration at higher doses $(1000,1500,2000$, and $3000 \mathrm{mg})$ in obese men with nonapparent endocrine disorder [116] or a diagnosed disorder $[117,118]$ for the same or longer treatment periods did not reveal beneficial effects on metabolic parameters and its known molecular targets. Also, single doses (250 and $500 \mathrm{mg}$ ) of orally administered RSV were shown to increase cerebral blood flow but revealed no effect on cognitive function in healthy humans [17]. However, RSV administration at a dose of $200 \mathrm{mg} /$ day for 26 weeks was reported to improve memory performance in addition to improving glucose metabolism [119]. Therefore, the dose and/or duration of RSV administration may influence outcomes in clinical trials and may differ between preventative or therapeutic clinical studies.

\section{Challenges in the Clinical Utility of Resveratrol in Diabetes Mellitus}

Numerous studies on the biological activity of RSV have been carried out in vitro and in animal models but there is so little human evidence. Unfortunately, studies conducted so far on the clinical utility of RSV in DM have been confronted with several limitations. The inherent cellular mechanisms underlying the antidiabetic effects of RSV deduced from preclinical data were not investigated properly in most of the studies. Single doses of RSV were employed in the studies, resulting in the lack of a proper understanding of doseresponse relationships.

Another limitation in the RSV clinical trials is sample size, involving only small cohorts of diabetic patients and the short duration of the trials. Long-term intervention studies are required to prove the efficacy of RSV and these are usually very expensive. RSV is a natural substance that is commercially available to everyone at a relatively cheap cost. This may partly explain the low interest of the pharmaceutical industry in investing funds on clinical studies to perform large-scale trials that would clarify the efficacy of RSV in DM.

In addition to the aforementioned limitations, the low bioavailability of RSV in humans poses another challenge in its use in DM [133]. The low bioavailability of RSV results from rapid glucuronidation, sulfation, and clearance from the body. This challenge is compounded by the fact that many bioavailability studies do not quantify tissue distribution and plasma bioavailability may not fully represent the RSV pool [134]. Therefore, the dosage required for optimal bioavailability for sufficient tissue distribution needs to be clarified. Human clinical trials are being performed currently without a full understanding of the optimal dosage protocols. Molecular target and efficacy of RSV may differ depending on the dose. Treatment with lower doses of RSV may activate SIRT1, whereas higher doses activate AMPK in a SIRT1independent manner. For example, in RSV treatment of C2C12 cells, a mouse skeletal muscle cell line at a dose of $25 \mu \mathrm{M}$ was reported to activate AMPK in a SIRT1-dependent manner, whereas a higher dose of $50 \mu \mathrm{M}$ activated AMPK in a SIRT1-independent manner [90].

\section{The Way Forward}

There is a strong correlation between RSV metabolism and its effectiveness. New approaches to increase the bioavailability of RSV can help to actualise its potentials as a therapeutic agent in DM and related complications. One of such approaches is the coadministration of RSV with compounds that act as substrate for enzymes involved in RSV metabolism. UDP-glucuronosyltransferase (UGT) and sulfotransferase (SULT) are key enzymes of RSV metabolism which catalyse glucuronidation and sulfation of RSV, respectively, enhancing its clearance from the body [134]. The combined effect of RSV and compounds that act as substrate for these enzymes may significantly increase the bioavailability of RSV.

Piperine is one of such compounds and has been shown to improve the effects and bioavailability of RSV in cell cultures and animal models. However, the outcome of the clinical trial on coadministration of RSV and piperine so far failed to improve bioavailability [135]. The lower dosage of piperine used in the human study which prevented a saturation of the UGT enzyme and had no effect on the rate of metabolite formation has been suggested as the reason for the observed effect. The additive effect of piperine and RSV needs to be further investigated. In addition, there are reports on the synergistic or additive effects of RSV and other polyphenols such as quercetin, catechin, curcumin, and genistein, although implication on bioavailability has not been investigated in many of the studies [54, 136-139]. A more recent study demonstrated an increase in skeletal muscle mitochondrial capacity in healthy humans administered RSV (500 mg) 
and piperine $(10 \mathrm{mg})$ supplementation as a bioenhancer to increase bioavailability and bioefficacy of RSV. However, a RSV only-supplemented group was not included in this study and bioavailability data was not available. Therefore, conclusions on improved effects and/or bioavailability of this combination in comparison to treatment with RSV only could not be reached [140].

In addition, the combination of RSV with genistein was reported to synergistically enhance antioxidant action in high-glucose treated Madin-Darby canine kidney (MDCK) epithelial cells when compared with RSV only and this combination may also have a therapeutic potential in diabetic nephropathy [141]. However, further studies are required to determine the effects of these combinations on the bioavailability of RSV and clinical relevance in diabetic conditions.

Long-term studies should be designed to determine appropriate dosage regimen and conclude on the antidiabetic effects of RSV in humans. Also, different new strategies such as the use of RSV nanoformulations, prodrugs, liposomemediated delivery, and implantable devices could be used to improve the antidiabetic efficacy of RSV. Some of these technologies have been investigated in animal studies [142, 143] with no report in humans. RSV prodrugs can be developed for improved efficacy in diabetics. Metabolism of prodrugs into RSV in tissues of interest can maximize tissue concentration and can be beneficial in the treatment of tissue specific complications in diabetic patients. Targeted delivery of RSV prodrugs into tissues of interest via delivery systems such as liposome-mediated delivery or nanotechnological approaches may result in improved therapeutic outcome. Also, intravenous injection as an alternative to traditional oral route of administration of RSV may bypass gastrointestinal absorption, conjugation, and hepatic metabolism, thus resulting in increased bioavailability and improved outcomes in diabetic patients.

RSV analogues with improved bioavailability, which can be administered either alone or in combination with other antidiabetic drugs, should be developed. The RSV molecule could be the primer for the development of other synthetic compounds that can be more bioavailable and of interest to pharmaceutical companies. In the bioavailability studies of RSV, red blood cells and tissue samples (such as muscle and adipose biopsy) should be included when it is ethical and clinically possible for a better assessment of RSV pool and tissue distribution.

\section{Conclusion}

The divergent mechanism of actions of resveratrol in vitro and in animals coupled with the reported health benefits in type 2 diabetic humans should be a driving force for conducting clinical research. The time is ripe to embark on large, well-controlled clinical studies to confirm the efficacy of resveratrol in the management of diabetes mellitus and gain a better insight into its biological effects in humans. In addition, the effective doses of resveratrol and treatment duration may differ between preventative and therapeutic trials. Therefore, it is important to investigate the dose dependent effects at varying treatment periods. A combinational approach as well as improved formulations of resveratrol may help to overcome the challenge of maintaining an effective concentration at the site of action for an appropriate period. By considering the aforementioned factors limiting clinical utility of resveratrol in subsequent studies, we may be able to use resveratrol or its analogue to treat or prevent diabetes mellitus in humans in the nearest future.

\section{Disclosure}

Omolola R. Oyenihi is currently affiliated to the Department of Biochemistry, University of Stellenbosch, Matieland, Stellenbosch, South Africa. Anne A. Adeyanju is currently affiliated to the Department of Biological Sciences, McPherson University, Seriki Sotayo, Ajebo, Ogun State, Nigeria.

\section{Competing Interests}

The authors declare that there is no competing interests regarding the publication of this manuscript.

\section{Authors' Contributions}

Omolola R. Oyenihi and Ayodeji B. Oyenihi were responsible for idea conception and design. Omolola R. Oyenihi, Ayodeji B. Oyenihi, Anne A. Adeyanju, and Oluwafemi O. Oguntibeju participated in drafting and revising the manuscript.

\section{References}

[1] A. Lançon, N. Hanet, B. Jannin et al., "Resveratrol in human hepatoma HepG2 cells: metabolism and inducibility of detoxifying enzymes," Drug Metabolism and Disposition, vol. 35, no. 5, pp. 699-703, 2007.

[2] U. Stervbo, O. Vang, and C. Bonnesen, "A review of the content of the putative chemopreventive phytoalexin resveratrol in red wine," Food Chemistry, vol. 101, no. 2, pp. 449-457, 2007.

[3] S. Bastianetto, C. Ménard, and R. Quirion, "Neuroprotective action of resveratrol," Biochimica et Biophysica Acta (BBA)Molecular Basis of Disease, vol. 1852, no. 6, pp. 1195-1201, 2015.

[4] B. Catalgol, S. Batirel, Y. Taga, and N. K. Ozer, "Resveratrol: french paradox revisited," Frontiers in Pharmacology, vol. 3, article 141, 2012.

[5] G. A. Potter, L. H. Patterson, E. Wanogho et al., "The cancer preventative agent resveratrol is converted to the anticancer agent piceatannol by the cytochrome P450 enzyme CYP1bl," British Journal of Cancer, vol. 86, no. 5, pp. 774-778, 2002.

[6] K. Ashikawa, S. Majumdar, S. Banerjee, A. C. Bharti, S. Shishodia, and B. B. Aggarwal, "Piceatannol inhibits TNFinduced NF- $\kappa \mathrm{B}$ activation and NF- $\kappa \mathrm{B}$-mediated gene expression through suppression of $\mathrm{I} \kappa \mathrm{B} \alpha$ kinase and $\mathrm{p} 65$ phosphorylation," Journal of Immunology, vol. 169, no. 11, pp. 6490-6497, 2002.

[7] T. Wieder, A. Prokop, B. Bagci et al., "Piceatannol, a hydroxylated analog of the chemopreventive agent resveratrol, is a potent inducer of apoptosis in the lymphoma cell line $\mathrm{BJAB}$ and in primary, leukemic lymphoblasts," Leukemia, vol. 15, no. 11, pp. 1735-1742, 2001. 
[8] Z. Ovesná and K. Horváthová-Kozics, "Structure-activity relationship of trans-resveratrol and its analogues," Neoplasma, vol. 52, no. 6, pp. 450-455, 2005.

[9] K. R. Patel, V. A. Brown, D. J. L. Jones et al., "Clinical pharmacology of resveratrol and its metabolites in colorectal cancer patients," Cancer Research, vol. 70, no. 19, pp. 7392-7399, 2010.

[10] A. Quincozes-Santos, L. D. Bobermin, A. Latini et al., "Resveratrol protects $\mathrm{C} 6$ astrocyte cell line against hydrogen peroxideinduced oxidative stress through heme oxygenase 1," PLoS ONE, vol. 8, no. 5, Article ID e64372, 2013.

[11] J. L. Bitterman and J. H. Chung, "Metabolic effects of resveratrol: addressing the controversies," Cellular and Molecular Life Sciences, vol. 72, no. 8, pp. 1473-1488, 2015.

[12] V. Ciddi and D. Dodda, "Therapeutic potential of resveratrol in diabetic complications: in vitro and in vivo studies," Pharmacological Reports, vol. 66, no. 5, pp. 799-803, 2014.

[13] B. N. M. Zordoky, I. M. Robertson, and J. R. B. Dyck, "Preclinical and clinical evidence for the role of resveratrol in the treatment of cardiovascular diseases," Biochimica et Biophysica Acta (BBA)-Molecular Basis of Disease, vol. 1852, no. 6, pp. 1155-1177, 2015.

[14] M. M. Poulsen, K. Fjeldborg, M. J. Ornstrup, T. N. Kjær, M. K. Nøhr, and S. B. Pedersen, "Resveratrol and inflammation: challenges in translating pre-clinical findings to improved patient outcomes," Biochimica et Biophysica Acta-Molecular Basis of Disease, vol. 1852, no. 6, pp. 1124-1136, 2015.

[15] B. Jiang, L. Guo, B.-Y. Li et al., "Resveratrol attenuates early diabetic nephropathy by down-regulating glutathione Stransferases $\mathrm{Mu}$ in diabetic rats," Journal of Medicinal Food, vol. 16, no. 6, pp. 481-486, 2013.

[16] J. K. Bhatt, S. Thomas, and M. J. Nanjan, "Resveratrol supplementation improves glycemic control in type 2 diabetes mellitus," Nutrition Research, vol. 32, no. 7, pp. 537-541, 2012.

[17] D. O. Kennedy, E. L. Wightman, J. L. Reay et al., "Effects of resveratrol on cerebral blood flow variables and cognitive performance in humans: a double-blind, placebo-controlled, crossover investigation," American Journal of Clinical Nutrition, vol. 91, no. 6, pp. 1590-1597, 2010.

[18] C. Rivière, T. Richard, X. Vitrac, J.-M. Mérillon, J. Valls, and J.P. Monti, "New polyphenols active on $\beta$-amyloid aggregation," Bioorganic and Medicinal Chemistry Letters, vol. 18, no. 2, pp. 828-831, 2008.

[19] C.-C. Chang, C.-Y. Chang, Y.-T. Wu, J.-P. Huang, T.-H. Yen, and L.-M. Hung, "Resveratrol retards progression of diabetic nephropathy through modulations of oxidative stress, proinflammatory cytokines, and AMP-activated protein kinase," Journal of Biomedical Science, vol. 18, no. 1, article no. 47, 2011.

[20] S. Kubota, Y. Ozawa, T. Kurihara et al., "Roles of AMP-activated protein kinase in diabetes-induced retinal inflammation," Investigative Ophthalmology and Visual Science, vol. 52, no. 12, pp. 9142-9148, 2011.

[21] A. S. Yar, S. Menevse, and E. Alp, “The effects of resveratrol on cyclooxygenase-1 and -2, nuclear factor kappa beta, matrix metalloproteinase-9, and sirtuin 1 mRNA expression in hearts of streptozotocin-induced diabetic rats," Genetics and Molecular Research, vol. 10, no. 4, pp. 2962-2975, 2011.

[22] R. Guo, B. Liu, K. Wang, S. Zhou, W. Li, and Y. Xu, "Resveratrol ameliorates diabetic vascular inflammation and macrophage infiltration in $\mathrm{db} / \mathrm{db}$ mice by inhibiting the NF- $\kappa \mathrm{B}$ pathway," Diabetes and Vascular Disease Research, vol. 11, no. 2, pp. 92102, 2014.
[23] B. Wang, Q. Yang, Y.-Y. Sun et al., "Resveratrol-enhanced autophagic flux ameliorates myocardial oxidative stress injury in diabetic mice," Journal of Cellular and Molecular Medicine, vol. 18, no. 8, pp. 1599-1611, 2014.

[24] P. Palsamy and S. Subramanian, "Resveratrol protects diabetic kidney by attenuating hyperglycemia-mediated oxidative stress and renal inflammatory cytokines via Nrf2-Keap1 signaling," Biochimica et Biophysica Acta-Molecular Basis of Disease, vol. 1812, no. 7, pp. 719-731, 2011.

[25] F. Xu, Y. Wang, W. Cui et al., "Resveratrol prevention of diabetic nephropathy is associated with the suppression of renal inflammation and mesangial cell proliferation: possible roles of Akt/NF- $\kappa$ B pathway," International Journal of Endocrinology, vol. 2014, Article ID 289327, 9 pages, 2014.

[26] IDF, IDF Diabetes Atlas, 7th edition, 2015.

[27] M. J. Fowler, "Microvascular and macrovascular complications of diabetes," Clinical Diabetes, vol. 26, no. 2, pp. 77-82, 2008.

[28] American Diabetes Association, "Diagnosis and classification of diabetes mellitus," Diabetes Care, vol. 32, supplement 1, pp. S62-S67, 2009.

[29] S. E. Kahn, "The relative contributions of insulin resistance and beta-cell dysfunction to the pathophysiology of Type 2 diabetes," Diabetologia, vol. 46, no. 1, pp. 3-19, 2003.

[30] J. C. Michael, M. C. James, and V. K. Robbins, "Pathalogic basis of disease," in The Pancreas, pp. 902-929, Harcourt, 6th edition, 2000.

[31] A. B. Oyenihi, A. O. Ayeleso, E. Mukwevho, and B. Masola, "Antioxidant strategies in the management of diabetic neuropathy," BioMed Research International, vol. 2015, Article ID 515042, 15 pages, 2015.

[32] T. Szkudelski and K. Szkudelska, "Resveratrol and diabetes: from animal to human studies," Biochimica et biophysica acta, vol. 1852, no. 6, pp. 1145-1154, 2015.

[33] A. Ambade and P. Mandrekar, "Oxidative stress and inflammation: essential partners in alcoholic liver disease," International Journal of Hepatology, vol. 2012, Article ID 853175, 9 pages, 2012.

[34] B. Halliwell and M. Whiteman, "Measuring reactive species and oxidative damage in vivo and in cell culture: how should you do it and what do the results mean?" British Journal of Pharmacology, vol. 142, no. 2, pp. 231-255, 2004.

[35] S. D. M. Bandeira, L. J. S. da Fonseca, G. D. S. Guedes, L. A. Rabelo, M. O. F. Goulart, and S. M. L. Vasconcelos, "Oxidative stress as an underlying contributor in the development of chronic complications in diabetes mellitus," International Journal of Molecular Sciences, vol. 14, no. 2, pp. 3265-3284, 2013.

[36] S. Z. Hasnain, J. B. Prins, and M. A. McGuckin, "Oxidative and endoplasmic reticulum stress in beta-cell dysfunction in diabetes," Journal of Molecular Endocrinology, vol. 56, no. 2, pp. R33-R54, 2016.

[37] F. Giacco and M. Brownlee, "Oxidative stress and diabetic complications," Circulation Research, vol. 107, no. 9, pp. 10581070, 2010.

[38] J. Styskal, H. Van Remmen, A. Richardson, and A. B. Salmon, "Oxidative stress and diabetes: what can we learn about insulin resistance from antioxidant mutant mouse models?" Free Radical Biology and Medicine, vol. 52, no. 1, pp. 46-58, 2012.

[39] P. Bansal and R. Kakkar, "Resveratrol: a polyphenol with multiple health benefits," International Journal of Pharmaceutics and Drug Analysis, vol. 2, no. 3, pp. 174-191, 2014.

[40] S. K. Biswas, "Does the interdependence between oxidative stress and inflammation explain the antioxidant paradox?" 
Oxidative Medicine and Cellular Longevity, vol. 2016, Article ID 5698931, 9 pages, 2016.

[41] J. M. Forbes and M. E. Cooper, "Mechanisms of diabetic complications," Physiological Reviews, vol. 93, no. 1, pp. 137-188, 2013.

[42] L. Wu, Y. Zhang, X. Ma, N. Zhang, and G. Qin, "The effect of resveratrol on FoxO1 expression in kidneys of diabetic nephropathy rats," Molecular Biology Reports, vol. 39, no. 9, pp. 9085-9093, 2012.

[43] H. Elbe, N. Vardi, M. Esrefoglu, B. Ates, S. Yologlu, and C. Taskapan, "Amelioration of streptozotocin-induced diabetic nephropathy by melatonin, quercetin, and resveratrol in rats," Human and Experimental Toxicology, vol. 34, no. 1, pp. 100-113, 2015.

[44] A. Kumar, R. K. Kaundal, S. Iyer, and S. S. Sharma, "Effects of resveratrol on nerve functions, oxidative stress and DNA fragmentation in experimental diabetic neuropathy," Life Sciences, vol. 80, no. 13, pp. 1236-1244, 2007.

[45] A. Kumar, G. Negi, and S. S. Sharma, "Neuroprotection by resveratrol in diabetic neuropathy: concepts \& mechanisms," Current Medicinal Chemistry, vol. 20, no. 36, pp. 4640-4645, 2013.

[46] J. Hua, K. I. Guerin, J. Chen et al., "Resveratrol inhibits pathologic retinal neovascularization in Vldlr-/- mice," Investigative Ophthalmology and Visual Science, vol. 52, no. 5, pp. 2809-2816, 2011.

[47] Y. H. Kim, Y. S. Kim, G. S. Roh, W. S. Choi, and G. J. Cho, "Resveratrol blocks diabetes-induced early vascular lesions and vascular endothelial growth factor induction in mouse retinas," Acta Ophthalmologica, vol. 90, no. 1, pp. e31-e37, 2012.

[48] F. G. Soufi, D. Mohammad-nejad, and H. Ahmadieh, "Resveratrol improves diabetic retinopathy possibly through oxidative stress-nuclear factor $\kappa \mathrm{B}$-apoptosis pathway," Pharmacological Reports, vol. 64, no. 6, pp. 1505-1514, 2012.

[49] O. M. A. Allah and F. El-Debakey, "Prophylactic resveratrol and telmisartan combination ameliorates experimentallyinduced diabetic nephropathy in rats, focus on the pro-sclerotic cytokine, transforming growth factor- $\beta 1$ (TGF- $\beta 1$ )," The Medical Journal of Cairo University, vol. 78, no. 2, 2010.

[50] R. K. Vella, C. Pullen, F. R. Coulson, and A. S. Fenning, "Resveratrol prevents cardiovascular complications in the SHR/STZ rat by reductions in oxidative stress and inflammation," BioMed Research International, vol. 2015, Article ID 918123, 8 pages, 2015.

[51] B. Turan, E. Tuncay, and G. Vassort, "Resveratrol and diabetic cardiac function: focus on recent in vitro and in vivo studies," Journal of Bioenergetics and Biomembranes, vol. 44, no. 2, pp. 281-296, 2012.

[52] M. Mohammadshahi, F. Haidari, and F. G. Soufi, "Chronic resveratrol administration improves diabetic cardiomyopathy in part by reducing oxidative stress," Cardiology Journal, vol. 21, no. 1, pp. 39-46, 2014.

[53] N. Hamadi, A. Mansour, M. H. Hassan, F. Khalifi-Touhami, and O. Badary, "Ameliorative effects of resveratrol on liver injury in streptozotocin-induced diabetic rats," Journal of Biochemical and Molecular Toxicology, vol. 26, no. 10, pp. 384-392, 2012.

[54] M. A. Hussein and H. A. El-Maksoud, "Biochemical effects of Resveratrol and curcumin combination on obese diabetic rats," Molecular \& Clinical Pharmacology, vol. 4, no. 1, pp. 1-10, 2013.

[55] J. L. Fiori, Y.-K. Shin, W. Kim et al., "Resveratrol prevents $\beta$-cell dedifferentiation in nonhuman primates given a high-fat/highsugar diet," Diabetes, vol. 62, no. 10, pp. 3500-3513, 2013.
[56] C. R. Ku, H. J. Lee, S. K. Kim, E. Y. Lee, M.-K. Lee, and E. J. Lee, "Resveratrol prevents streptozotocin-induced diabetes by inhibiting the apoptosis of pancreatic $\beta$-cell and the cleavage of poly (ADP-ribose) polymerase," Endocrine Journal, vol. 59, no. 2, pp. 103-109, 2012.

[57] C.-C. Chang, M.-H. Yang, H.-C. Tung et al., "Resveratrol exhibits differential protective effects on fast- and slow-twitch muscles in streptozotocin-induced diabetic rats," Journal of Diabetes, vol. 6, no. 1, pp. 60-67, 2014.

[58] H.-C. Su, L.-M. Hung, and J.-K. Chen, "Resveratrol, a red wine antioxidant, possesses an insulin-like effect in streptozotocininduced diabetic rats," American Journal of PhysiologyEndocrinology and Metabolism, vol. 290, no. 6, pp. E1339-E1346, 2006.

[59] S. V. Penumathsa, M. Thirunavukkarasu, L. Zhan et al., "Resveratrol enhances GLUT-4 translocation to the caveolar lipid raft fractions through AMPK/Akt/eNOS signalling pathway in diabetic myocardium," Journal of Cellular and Molecular Medicine, vol. 12, no. 6, pp. 2350-2361, 2008.

[60] K. H. Chen, M. L. Cheng, Y. H. Jing, D. T. Chiu, M. S. Shiao, and J. K. Chen, "Resveratrol ameliorates metabolic disorders and muscle wasting in streptozotocin-induced diabetic rats," The American Journal of Physiology-Endocrinology and Metabolism, vol. 301, no. 5, pp. E853-E863, 2011.

[61] D. M. Nathan, M. B. Davidson, R. A. DeFronzo et al., "Impaired fasting glucose and impaired glucose tolerance: implications for care," Diabetes Care, vol. 30, no. 3, pp. 753-759, 2007.

[62] J. A. Baur, K. J. Pearson, N. L. Price et al., "Resveratrol improves health and survival of mice on a high-calorie diet," Nature, vol. 444, no. 7117, pp. 337-342, 2006.

[63] M. Lagouge, C. Argmann, Z. Gerhart-Hines et al., "Resveratrol improves mitochondrial function and protects against metabolic disease by activating SIRT1 and PGC-1 $\alpha$," Cell, vol. 127, no. 6, pp. 1109-1122, 2006.

[64] Y.-E. Lee, J.-W. Kim, E.-M. Lee et al., "Chronic resveratrol treatment protects pancreatic islets against oxidative stress in db/db mice," PLoS ONE, vol. 7, no. 11, Article ID e50412, 2012.

[65] M.-S. Beaudoin, L. A. Snook, A. M. Arkell, J. A. Simpson, G. P. Holloway, and D. C. Wright, "Resveratrol supplementation improves white adipose tissue function in a depot-specific manner in Zucker diabetic fatty rats," American Journal of Physiology-Regulatory Integrative and Comparative Physiology, vol. 305, no. 5, pp. R542-R551, 2013.

[66] J.-H. Um, S.-J. Park, H. Kang et al., "AMP-activated protein kinase-deficient mice are resistant to the metabolic effects of resveratrol," Diabetes, vol. 59, no. 3, pp. 554-563, 2010.

[67] J. Marchal, S. Blanc, J. Epelbaum, F. Aujard, and F. Pifferi, "Effects of chronic calorie restriction or dietary resveratrol supplementation on insulin sensitivity markers in a primate, microcebus murinus," PLoS ONE, vol. 7, no. 3, Article ID e34289, 2012.

[68] J. R. Zierath and Y. Kawano, "The effect of hyperglycaemia on glucose disposal and insulin signal transduction in skeletal muscle," Best Practice and Research: Clinical Endocrinology and Metabolism, vol. 17, no. 3, pp. 385-398, 2003.

[69] D. Pitocco, F. Zaccardi, E. Di Stasio et al., "Oxidative stress, nitric oxide, and diabetes," Review of Diabetic Studies, vol. 7, no. 1, pp. 15-25, 2010.

[70] M. Thirunavukkarasu, S. V. Penumathsa, S. Koneru et al., "Resveratrol alleviates cardiac dysfunction in streptozotocininduced diabetes: role of nitric oxide, thioredoxin, and heme 
oxygenase," Free Radical Biology and Medicine, vol. 43, no. 5, pp. 720-729, 2007.

[71] Á. González-Rodríguez, B. Santamaría, J. A. Mas-Gutierrez et al., "Resveratrol treatment restores peripheral insulin sensitivity in diabetic mice in a sirtl-independent manner," Molecular Nutrition and Food Research, vol. 59, no. 8, pp. 1431-1442, 2015.

[72] H. Moridi, J. Karimi, N. Sheikh et al., "Resveratrol-dependent down-regulation of receptor for advanced glycation endproducts and oxidative stress in kidney of rats with diabetes," International Journal of Endocrinology and Metabolism, vol. 13, no. 2, Article ID e23542, 2015.

[73] M. Khazaei, J. Karimi, N. Sheikh et al., "Effects of resveratrol on receptor for advanced glycation end products (RAGE) expression and oxidative stress in the liver of rats with type 2 diabetes," Phytotherapy Research, vol. 30, no. 1, pp. 66-71, 2016.

[74] N. Chaudhary and P. T. Pfluger, "Metabolic benefits from Sirt1 and Sirtl activators," Current Opinion in Clinical Nutrition and Metabolic Care, vol. 12, no. 4, pp. 431-437, 2009.

[75] J. C. Milne, P. D. Lambert, S. Schenk et al., "Small molecule activators of SIRT1 as therapeutics for the treatment of type 2 diabetes," Nature, vol. 450, no. 7170, pp. 712-716, 2007.

[76] S. V. De Kreutzenberg, G. Ceolotto, I. Papparella et al., "Downregulation of the longevity-associated protein sirtuin 1 in insulin resistance and metabolic syndrome: potential biochemical mechanisms," Diabetes, vol. 59, no. 4, pp. 10061015, 2010.

[77] G. Ramadori, L. Gautron, T. Fujikawa, C. R. Vianna, J. K. Elmquist, and R. Coppari, "Central administration of resveratrol improves diet-induced diabetes," Endocrinology, vol. 150, no. 12, pp. 5326-5333, 2009.

[78] C. D. Côté, B. A. Rasmussen, F. A. Duca et al., "Resveratrol activates duodenal Sirtl to reverse insulin resistance in rats through a neuronal network," Nature Medicine, vol. 21, no. 5, pp. 498-505, 2015.

[79] B. Bordone and L. Guarente, "Sirtuins and $\beta$-cell function," Diabetes, Obesity and Metabolism, vol. 9, no. 2, pp. 23-27, 2007.

[80] Y. I. Kitamura, T. Kitamura, J.-P. Kruse et al., "FoxO1 protects against pancreatic $\beta$ cell failure through NeuroD and MafA induction," Cell Metabolism, vol. 2, no. 3, pp. 153-163, 2005.

[81] K. Turkmen, A. Karagoz, and A. Kucuk, "Sirtuins as novel players in the pathogenesis of diabetes mellitus," World Journal of Diabetes, vol. 5, no. 6, pp. 894-900, 2014.

[82] K. Hasegawa, S. Wakino, K. Yoshioka et al., "Sirtl protects against oxidative stress-induced renal tubular cell apoptosis by the bidirectional regulation of catalase expression," Biochemical and Biophysical Research Communications, vol. 372, no. 1, pp. 51-56, 2008.

[83] P. T. Pfluger, D. Herranz, S. Velasco-Miguel, M. Serrano, and M. H. Tschöp, "Sirtl protects against high-fat diet-induced metabolic damage," Proceedings of the National Academy of Sciences of the United States of America, vol. 105, no. 28, pp. 9793-9798, 2008.

[84] K. A. Moynihan, A. A. Grimm, M. M. Plueger et al., "Increased dosage of mammalian Sir2 in pancreatic $\beta$ cells enhances glucose-stimulated insulin secretion in mice," Cell Metabolism, vol. 2, no. 2, pp. 105-117, 2005.

[85] K. M. Ramsey, K. F. Mills, A. Satoh, and S.-I. Imai, "Ageassociated loss of Sirtl-mediated enhancement of glucosestimulated insulin secretion in beta cell-specific Sirtl-overexpressing (BESTO) mice," Aging Cell, vol. 7, no. 1, pp. 78-88, 2008.
[86] M. Kitada and D. Koya, "SIRT1 in type 2 diabetes: mechanisms and therapeutic potential," Diabetes and Metabolism Journal, vol. 37, no. 5, pp. 315-325, 2013.

[87] S. S. Kulkarni and C. Cantó, "The molecular targets of resveratrol," Biochimica et Biophysica Acta-Molecular Basis of Disease, vol. 1852, no. 6, pp. 1114-1123, 2015.

[88] M.-J. Lee, D. Feliers, M. M. Mariappan et al., "A role for AMPactivated protein kinase in diabetes-induced renal hypertrophy," American Journal of Physiology-Renal Physiology, vol. 292, no. 2, pp. F617-F627, 2007.

[89] K.-H. Chen, C.-C. Hung, H.-H. Hsu, Y.-H. Jing, C.-W. Yang, and J.-K. Chen, "Resveratrol ameliorates early diabetic nephropathy associated with suppression of augmented TGF- $\beta /$ smad and ERK1/2 signaling in streptozotocin-induced diabetic rats," Chemico-Biological Interactions, vol. 190, no. 1, pp. 45-53, 2011.

[90] N. L. Price, A. P. Gomes, A. J. Y. Ling et al., "SIRT1 is required for AMPK activation and the beneficial effects of resveratrol on mitochondrial function," Cell Metabolism, vol. 15, no. 5, pp. 675690, 2012.

[91] C.-C. Chang, C.-Y. Chang, J.-P. Huang, and L.-M. Hung, "Effect of resveratrol on oxidative and inflammatory stress in liver and spleen of streptozotocin-induced type 1 diabetic rats," Chinese Journal of Physiology, vol. 55, no. 3, pp. 192-201, 2012.

[92] R. Schmatz, L. B. Perreira, N. Stefanello et al., "Effects of resveratrol on biomarkers of oxidative stress and on the activity of delta aminolevulinic acid dehydratase in liver and kidney of streptozotocin-induced diabetic rats," Biochimie, vol. 94, no. 2, pp. 374-383, 2012.

[93] K. Carolo dos Santos, C. Pereira Braga, P. Octavio Barbanera, F. R. F. Seiva, A. Fernandes Jr., and A. A. H. Fernandes, "Cardiac energy metabolism and oxidative stress biomarkers in diabetic rat treated with resveratrol," PLoS ONE, vol. 9, no. 7, Article ID e102775, 2014.

[94] M. Kitada, S. Kume, N. Imaizumi, and D. Koya, "Resveratrol improves oxidative stress and protects against diabetic nephropathy through normalization of Mn-SOD dysfunction in AMPK/SIRT1-independent pathway," Diabetes, vol. 60, no. 2, pp. 634-643, 2011.

[95] S. Khamneh, F. G. Soufi, and F. Afshar, "Long-term resveratrol administration reduces renal oxidative stress and apoptosis rate in experimental model of type 2 diabetes," Life Science Journal, vol. 9, no. 4, pp. 2997-3001, 2012.

[96] H. E. Mohamed, S. E. El-Swefy, R. A. Hasan, and A. A. Hasan, "Neuroprotective effect of resveratrol in diabetic cerebral ischemic-reperfused rats through regulation of inflammatory and apoptotic events," Diabetology \& Metabolic Syndrome, vol. 6, no. 1, article 88, 2014.

[97] E. Yulug, S. Tured, A. Alver, O. Kutlu, E. Karaguzel, and C. Kahraman, "Effects of resveratrol on testis damage in streptozotocin induced diabetic rats," Journal of Animal and Veterinary Advances, vol. 12, no. 6, pp. 747-753, 2013.

[98] J. Jeong, M. J. Conboy, and I. M. Conboy, "Sirtl-independent rescue of muscle regeneration by resveratrol in type I diabetes," Journal of Diabetes \& Metabolism, vol. 4, article 289, 2013.

[99] M. C. Haigis and L. P. Guarente, "Mammalian sirtuinsemerging roles in physiology, aging, and calorie restriction," Genes \& Development, vol. 20, no. 21, pp. 2913-2921, 2006.

[100] S. Michan and D. Sinclair, "Sirtuins in mammals: insights into their biological function," Biochemical Journal, vol. 404, no. 1, pp. 1-13, 2007.

[101] D.-W. Park, K. Baek, J.-R. Kim et al., "Resveratrol inhibits foam cell formation via NADPH oxidase 1-mediated reactive oxygen 
species and monocyte chemotactic protein-1," Experimental and Molecular Medicine, vol. 41, no. 3, pp. 171-179, 2009.

[102] Z. Ungvari, N. Labinskyy, P. Mukhopadhyay et al., "Resveratrol attenuates mitochondrial oxidative stress in coronary arterial endothelial cells," American Journal of Physiology-Heart and Circulatory Physiology, vol. 297, no. 5, pp. H1876-H1881, 2009.

[103] L. M. Pedruzzi, M. B. Stockler-Pinto, M. Leite Jr., and D. Mafra, "Nrf2-keap1 system versus NF- $\kappa$ B: the good and the evil in chronic kidney disease?" Biochimie, vol. 94, no. 12, pp. 24612466, 2012.

[104] A. A. Elmarakby and J. C. Sullivan, "Relationship between oxidative stress and inflammatory cytokines in diabetic nephropathy," Cardiovascular Therapeutics, vol. 30, no. 1, pp. 49-59, 2012.

[105] T. Lawrence, "The nuclear factor NF- $\kappa$ B pathway in inflammation," Cold Spring Harbor Perspectives in Biology, vol. 1, no. 6, Article ID a001651, 2009.

[106] A. Kumar and S. S. Sharma, "NF- $\kappa$ B inhibitory action of resveratrol: a probable mechanism of neuroprotection in experimental diabetic neuropathy," Biochemical and Biophysical Research Communications, vol. 394, no. 2, pp. 360-365, 2010.

[107] O. Prabhakar, "Cerebroprotective effect of resveratrol through antioxidant and anti-inflammatory effects in diabetic rats," Naunyn-Schmiedeberg's Archives of Pharmacology, vol. 386, no. 8, pp. 705-710, 2013.

[108] X.-D. Lou, H.-D. Wang, S.-J. Xia, S. Skog, and J. Sun, "Effects of resveratrol on the expression and DNA methylation of cytokine genes in diabetic rat aortas," Archivum Immunologiae et Therapiae Experimentalis, vol. 62, no. 4, pp. 329-340, 2014.

[109] S.-M. Lee, H. Yang, D. M. Tartar et al., "Prevention and treatment of diabetes with resveratrol in a non-obese mouse model of type 1 diabetes," Diabetologia, vol. 54, no. 5, pp. 11361146, 2011.

[110] H. Zhang, J. Zhang, Z. Ungvari, and C. Zhang, "Resveratrol improves endothelial function. Role of TNF $\alpha$ and vascular oxidative stress," Arteriosclerosis, Thrombosis, and Vascular Biology, vol. 29, no. 8, pp. 1164-1171, 2009.

[111] A. Movahed, I. Nabipour, X. L. Louis et al., "Antihyperglycemic effects of short term resveratrol supplementation in type 2 diabetic patients," Evidence-Based Complementary and Alternative Medicine, vol. 2013, Article ID 851267, 11 pages, 2013.

[112] P. Brasnyó, G. A. Molnár, M. Mohás et al., "Resveratrol improves insulin sensitivity, reduces oxidative stress and activates the Akt pathway in type 2 diabetic patients," British Journal of Nutrition, vol. 106, no. 3, pp. 383-389, 2011.

[113] Y. K. Bashmakov, S. H. Assaad-Khalil, M. Abou Seif et al., "Resveratrol Promotes Foot Ulcer Size Reduction in Type 2 Diabetes Patients," ISRN Endocrinology, vol. 2014, Article ID 816307, 8 pages, 2014.

[114] S. Timmers, E. Konings, L. Bilet et al., "Calorie restrictionlike effects of 30 days of resveratrol supplementation on energy metabolism and metabolic profile in obese humans," Cell Metabolism, vol. 14, no. 5, pp. 612-622, 2011.

[115] B. Agarwal, M. J. Campen, M. M. Channell et al., "Resveratrol for primary prevention of atherosclerosis: clinical trial evidence for improved gene expression in vascular endothelium," International Journal of Cardiology, vol. 166, no. 1, pp. 246-248, 2013.

[116] M. M. Poulsen, P. F. Vestergaard, B. F. Clasen et al., "Highdose resveratrol supplementation in obese men: an investigatorinitiated, randomized, placebo-controlled clinical trial of substrate metabolism, insulin sensitivity, and body composition," Diabetes, vol. 62, no. 4, pp. 1186-1195, 2013.
[117] S. Dash, C. Xiao, C. Morgantini, L. Szeto, and G. F. Lewis, "High-dose resveratrol treatment for 2 weeks inhibits intestinal and hepatic lipoprotein production in overweight/obese men," Arteriosclerosis, Thrombosis, and Vascular Biology, vol. 33, no. 12, pp. 2895-2901, 2013.

[118] V. S. Chachay, G. A. Macdonald, J. H. Martin et al., "Resveratrol does not benefit patients with nonalcoholic fatty liver disease," Clinical Gastroenterology and Hepatology, vol. 12, no. 12, pp. 2092-2103, 2014.

[119] A. V. Witte, L. Kerti, D. S. Margulies, and A. Flöel, "Effects of resveratrol on memory performance, hippocampal functional connectivity, and glucose metabolism in healthy older adults," The Journal of Neuroscience, vol. 34, no. 23, pp. 7862-7870, 2014.

[120] M. M. Shahi, F. Haidari, and M. R. Shiri, "Comparison of effect of resveratrol and vanadium on diabetes related dyslipidemia and hyperglycemia in streptozotocin induced diabetic rats," Advanced Pharmaceutical Bulletin, vol. 1, no. 2, pp. 81-86, 2011.

[121] A.-S. Cheng, Y.-H. Cheng, C.-Y. Lee, C.-Y. Chung, and W.C. Chang, "Resveratrol protects against methylglyoxal-induced hyperglycemia and pancreatic damage in vivo," Nutrients, vol. 7 , no. 4, pp. 2850-2865, 2015.

[122] S. Pereira, E. Park, J. Moore et al., "Resveratrol prevents insulin resistance caused by short-term elevation of free fatty acids in vivo," Applied Physiology, Nutrition and Metabolism, vol. 40, no. 11, pp. 1129-1136, 2015.

[123] J. Burns, T. Yokota, H. Ashihara, M. E. J. Lean, and A. Crozier, "Plant foods and herbal sources of resveratrol," Journal of Agricultural and Food Chemistry, vol. 50, no. 11, pp. 3337-3340, 2002.

[124] C. Counet, D. Callemien, and S. Collin, "Chocolate and cocoa: new sources of trans-resveratrol and trans-piceid," Food Chemistry, vol. 98, no. 4, pp. 649-657, 2006.

[125] W. J. Hurst, J. A. Glinski, K. B. Miller, J. Apgar, M. H. Davey, and D. A. Stuart, "Survey of the trans-resveratrol and trans-piceid content of cocoa-containing and chocolate products," Journal of Agricultural and Food Chemistry, vol. 56, no. 18, pp. 8374-8378, 2008.

[126] S. Mukherjee, J. I. Dudley, and D. K. Das, "Dose-dependency of resveratrol in providing health benefits," Dose-Response, vol. 8, no. 4, pp. 478-500, 2010.

[127] Y. K. Bashmakov, S. Assaad-Khalil, and I. M. Petyaev, "Resveratrol may be beneficial in treatment of diabetic foot syndrome," Medical Hypotheses, vol. 77, no. 3, pp. 364-367, 2011.

[128] J. Tomé-Carneiro, M. Larrosa, M. J. Yáñez-Gascón et al., "One-year supplementation with a grape extract containing resveratrol modulates inflammatory-related microRNAs and cytokines expression in peripheral blood mononuclear cells of type 2 diabetes and hypertensive patients with coronary artery disease," Pharmacological Research, vol. 72, pp. 69-82, 2013.

[129] J. Yoshino, C. Conte, L. Fontana et al., "Resveratrol supplementation does not improve metabolic function in nonobese women with normal glucose tolerance," Cell Metabolism, vol. 16, no. 5, pp. 658-664, 2012.

[130] J. P. Crandall, V. Oram, G. Trandafirescu et al., "Pilot study of resveratrol in older adults with impaired glucose tolerance," The Journals of Gerontology Series A: Biological Sciences and Medical Sciences, vol. 67, no. 12, pp. 1307-1312, 2012.

[131] C. Militaru, I. Donoiu, A. Craciun, I. D. Scorei, A. M. Bulearca, and R. I. Scorei, "Oral resveratrol and calcium fructoborate supplementation in subjects with stable angina pectoris: effects on lipid profiles, inflammation markers, and quality of life," Nutrition, vol. 29, no. 1, pp. 178-183, 2013. 
[132] J. Tomé-Carneiro, M. Gonzálvez, M. Larrosa et al., “One-year consumption of a grape nutraceutical containing resveratrol improves the inflammatory and fibrinolytic status of patients in primary prevention of cardiovascular disease," American Journal of Cardiology, vol. 110, no. 3, pp. 356-363, 2012.

[133] T. Walle, M. H. De Legge, R. E. Hypolite, J. T. Lucas, and U. K. Walle, "Resveratrol-[C-14] disposition and metabolism in vivo in humans," The FASEB Journal, vol. 18, no. 4, p. A604, 2004.

[134] J. M. Smoliga and O. Blanchard, "Enhancing the delivery of resveratrol in humans: if low bioavailability is the problem, what is the solution?" Molecules, vol. 19, no. 11, pp. 17154-17172, 2014.

[135] E. L. Wightman, J. L. Reay, C. F. Haskell, G. Williamson, T. P. Dew, and D. O. Kennedy, "Effects of resveratrol alone or in combination with piperine on cerebral blood flow parameters and cognitive performance in human subjects: a randomised, double-blind, placebo-controlled, cross-over investigation," British Journal of Nutrition, vol. 112, no. 2, pp. 203213, 2014.

[136] H. J. Park, J.-Y. Yang, S. Ambati et al., "Combined effects of genistein, quercetin, and resveratrol in human and 3T3-L1 adipocytes," Journal of Medicinal Food, vol. 11, no. 4, pp. 773783, 2008.

[137] A. Schlachterman, F. Valle, K. M. Wall et al., "Combined resveratrol, quercetin, and catechin treatment reduces breast tumor growth in a nude mouse model," Translational Oncology, vol. 1, no. 1, pp. 19-27, 2008.

[138] S. Rayalam, M. A. Della-Fera, and C. A. Baile, "Synergism between resveratrol and other phytochemicals: implications for obesity and osteoporosis," Molecular Nutrition \& Food Research, vol. 55, no. 8, pp. 1177-1185, 2011.

[139] C. K. Singh, J. George, and N. Ahmad, "Resveratrol-based combinatorial strategies for cancer management," Annals of the New York Academy of Sciences, vol. 1290, no. 1, pp. 113-121, 2013.

[140] K. R. Polley, N. Jenkins, P. O'Connor, and K. McCully, "Influence of exercise training with resveratrol supplementation on skeletal muscle mitochondrial capacity," Applied Physiology, Nutrition and Metabolism, vol. 41, no. 1, pp. 26-32, 2015.

[141] C. Chu, F. J. Lu, R. H. Yeh, Z. L. Li, and C. H. Chen, "Synergistic antioxidant activity of resveratrol with genistein in high-glucose treated Madin-Darby canine kidney epithelial cells," Biomedical Reports, vol. 4, no. 3, pp. 349-354, 2016.

[142] R. L. Frozza, A. Bernardi, K. Paese et al., "Characterization of trans-resveratrol-loaded lipid-core nanocapsules and tissue distribution studies in rats," Journal of Biomedical Nanotechnology, vol. 6, no. 6, pp. 694-703, 2010.

[143] L. Liang, X. Liu, Q. Wang, S. Cheng, S. Zhang, and M. Zhang, "Pharmacokinetics, tissue distribution and excretion study of resveratrol and its prodrug 3,5,4/-tri- $O$-acetylresveratrol in rats," Phytomedicine, vol. 20, no. 6, pp. 558-563, 2013. 


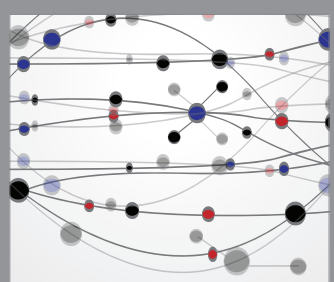

The Scientific World Journal
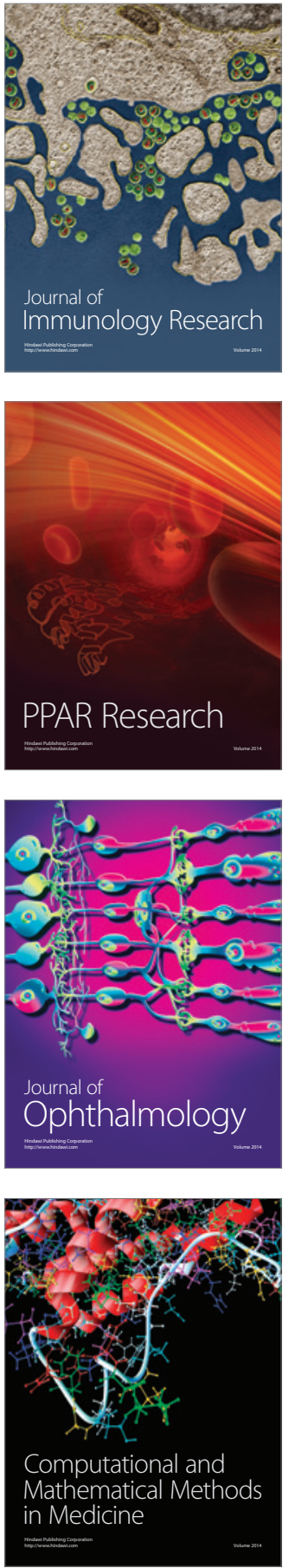

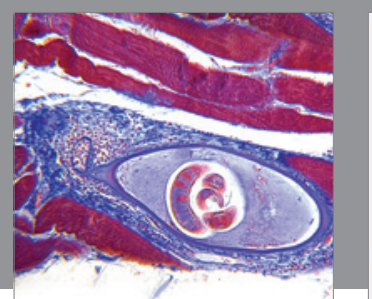

Gastroenterology Research and Practice

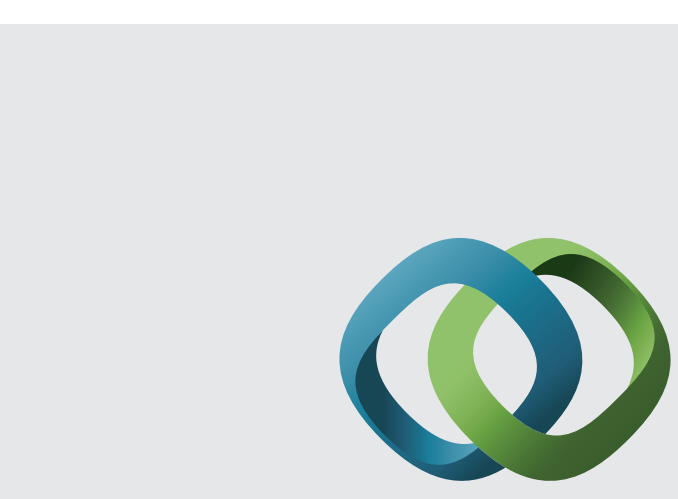

\section{Hindawi}

Submit your manuscripts at

http://www.hindawi.com
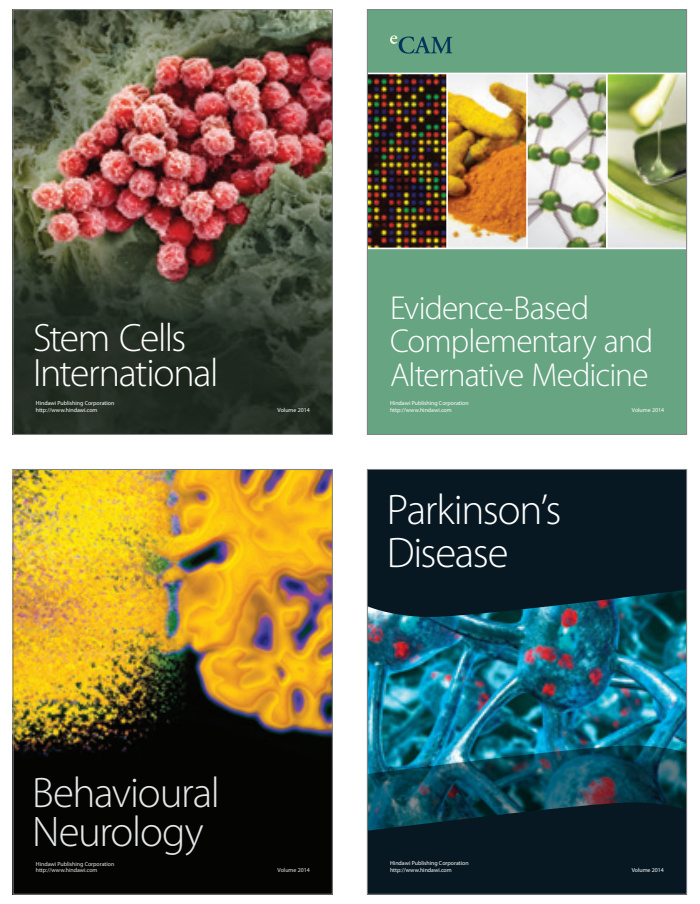
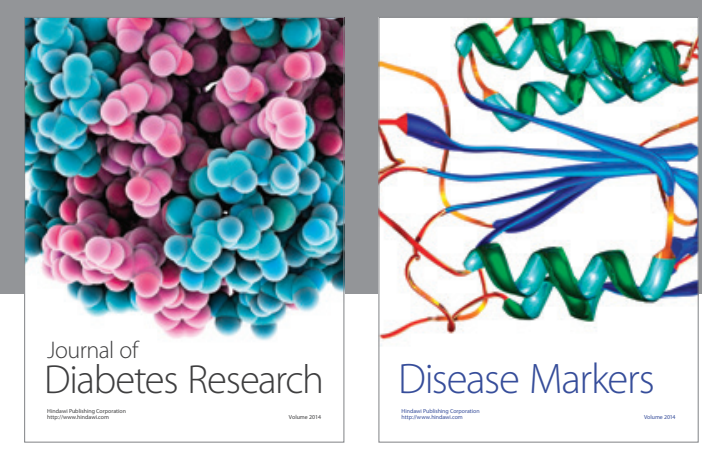

Disease Markers
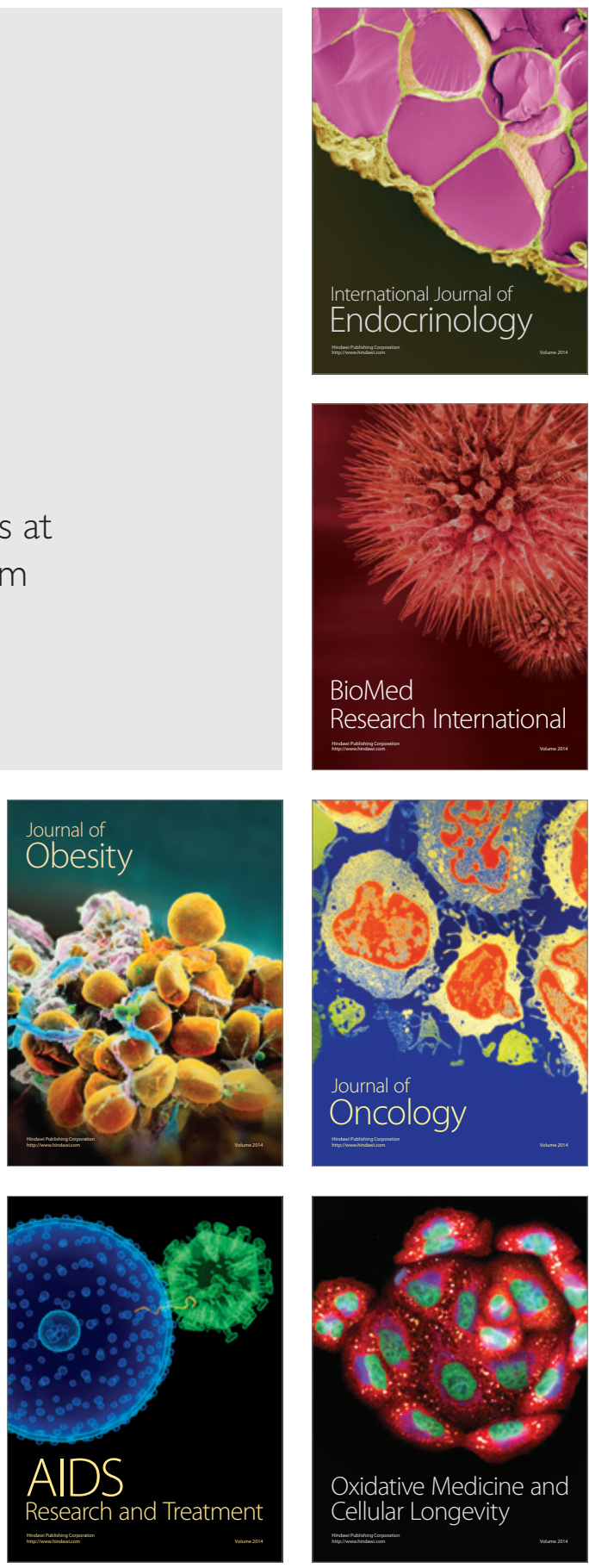